\title{
In situ data supporting remote sensing estimation of spruce forest parameters at the ecosystem station Bílý Křriž
}

\author{
*Lucie Homolová1, Růžena Janoutová1, Petr Lukeš1, Jan Hanuš1, Jan Novotný1, \\ Olga Brovkina ${ }^{1}$, Rolling Richard Loayza Fernandez ${ }^{1}$ \\ 1) Global Change Research Institute CAS, Bëlidla 986/4a, 60300 Brno, Czech Republic, \\ e-mail: homolova.l, lukes.p, janoutova.r, hanus.j,novotny.j, brovkina.o,loyaza.r@czechglobe.cz
}

\begin{abstract}
Homolová L., Janoutová R.,Lukeš P., Hanuš J., Novotný J., Brovkina O., Loayza Fernandez R. R. 2017: In situ data collection supporting remote sensing estimation of spruce forest parameters at the ecosystem station Bílý Kř́ž - Beskydy, 10 (1, 2): 75-86

Remote sensing offers an effective way of mapping vegetation parameters in a spatially continuous manner, at larger spatial scales and repeatedly in time compared to traditional in situ mapping approaches that are typically accurate, but limited to a few distributed location and few repetitions. In case of forest ecosystems, remote sensing allow to assess quantitative parameters or indicators related to forest health status such as leaf area index, leaf pigment content, chlorophyll fluorescence, etc. Development, calibration and validation of remote sensing-based methods, however, still rely on supportive in situ data. The aim of this contribution is to introduce the individual in situ components in the framework for the retrieval of forest quantitative parameters from airborne imaging spectroscopy data. All measurements were acquired during an extensive in situ/flight campaign that took place at the Norway spruce dominated study site Bílý Kř́iž (MoravianSilesian Beskydy Mts., Czech Republic) during August 2016. In addition to airborne remote sensing data acquisition, the in situ activities included terrestrial laser scanning for tree 3D modelling, measurements of needle biochemical and optical properties, leaf area index measurements and spectral measurements of various natural and artificial surfaces. Leaf pigments varied between 25.2 and $49.1 \mu \mathrm{g} \mathrm{cm}^{-2}$ for chlorophyll a+b content, 4.9 - $10.6 \mu \mathrm{g} \mathrm{cm}{ }^{-2}$ for carotenoid content depending on needle age and its adaptation to sun illumination, whereas ratio between the two pigments was stable around 4.6 -5.3. Specific leaf area of spruce needles varied between 49.3 and $105.8 \mathrm{~cm}^{2} \mathrm{~g}^{-1}$, being the highest for the shade adapted needles of the current year. Leaf area index of spruce stands of various age and densities varied between 5.3 and 9.3.
\end{abstract}

Keywords: Airborne imaging spectroscopy, terrestrial laser scanning, leaf area index, chlorophyll content, Picea abies, radiative transfer modelling

\section{Introduction}

Remote sensing (RS) is a powerful tool for studying forest ecosystems both in space and time (Cohen and Goward 2004; Lausch et al. 2016 \& 2017). In particular, airborne imaging spectroscopy (or hyperspectral RS), which offers unique combination of high spatial and spectral resolution data (Schaepman 2009), can be used to retrieve quantitative parameters on forest stands such as leaf biochemical properties including pigments, water, nitrogen content (Asner et al. 2015; Kokaly et al., 2009; Malenovský et al. 2013) leaf area index (Heiskanen et al. 2013; Schlerf and Atzberger 2006) and most recently also parameters related to plant photosynthesis such as leaf chlorophyll fluorescence (Rossini et al. 2015; Middelton et al. 2017). Often, retrievals of 
forest parameters from imaging spectroscopy data rely on the inversion of radiative transfer models (Banskota et al. 2015; Laurent et al. 2011; Malenovský et al., 2013). Radiative transfer models (RTMs) simulate interactions between incoming radiation and landscape elements (e.g., trees) and thus are able to compute the top-of-canopy reflectance, i.e. the same signal as captured by imaging spectrometers for varying sun-target-sensor geometries and combinations of key input variables (i.e., canopy structures, forest densities, leaf optical properties). Forest landscape representation in an RTM may vary from a simple multi-layer model representing forest as homogeneous medium (e.g., SAIL; Jacquemoud et al. 2009; Verhoef and Bach 2007) to a complex model with explicit 3D canopy structure (e.g., DART - Discrete Anisotropic Radiative Transfer model; Gastellu-Etchegorry et al. 2015). Interpretation of high spatial resolution airborne imagery require corresponding level of details in the associated RTMs, therefore complex 3D RTMs are better suited that simple ID models. Forest canopies, particularly conifers, are challenging objects to be modelled in $3 \mathrm{D}$ radiative transfer, especially for their distinct crown shape and highly organized crown architecture, complex light interactions at the level of the main scattering elements (i.e. needle shoots) and often the presence of understory (Eriksson et al., 2006; Malenovský et al., 2008; Rautiainen et al., 2004; Rochdi et al., 2006).

While remote sensing technologies are able to detect forest data in high quality and large quantity, operational applications are still limited by insufficient in situ verification (Pause et al. 2016). In addition to the acquisition of RS data, supportive in situ data are required for parameterization of RTMs, constraining the retrieval algorithms and last but not least verification of remotely sensed estimates of forest parameters. This paper aims to demonstrate the importance and the irreplaceable role of in situ measurements in the context of quantitative remote sensing of coniferous forests. We present here methods for in situ data collection, results of the measurements and how the in situ component fits into the framework for the retrieval of forest quantitative parameters from airborne hyperspectral sensing. Data were collected within an extensive in situ/airborne campaign that took a place at the Bílý Kř́ž study site in summer 2016. This campaign mainly supported CzechGlobe's research projects for the European Space Agency (ESA).

\section{Material and Methods}

\section{Study area}

The combined in situ and flight campaign took place at the vicinity of the ecosystem station Bílý Kř́ž in the Moravian-Silesian Beskydy Mts. (Czech Republic, 49³0'N, 18²' E, 800920 m a.s.l.) in August 2016. This site is used for long-term research on tree ecophysiology and carbon fluxes as a part of national (Czech Carbon Observation System CzeCOS) and international (Integrated Carbon Observation System ICOS) research networks (Krupková et al. 2017; Urban et al. 2012). The site is covered predominantly by Norway spruce (Picea abies) monocultures of different age.

For the in situ measurements, seven plots were selected in the vicinity of the ecosystem station, covering spruce stands of different age, densities and site conditions (topography). Location of the plots and the schematic sampling design for measurements of leaf properties and leaf area index (LAI) are shown in Fig. 1.

\section{Measurements of leaf biochemical and optical properties}

Leaf properties, namely leaf chlorophyll $a+b$ and carotenoids content, leaf water content, leaf mass per area and leaf optical properties (reflectance and transmittance) were measured at the peak of the growing season at the end of August 2016. As such, they are compatible with airborne hyperspectral images acquired on $31^{\text {st }}$ August of the same year. Needle samples were collected from three representative trees selected within each of the seven plots. Current, one and twoyears-old shoots were cut off from two branches representing sunlit (i.e., crown top) and shaded (i.e., crown bottom) illumination conditions. Six samples were analysed for each tree, resulting in 126 needle samples in total.

Leaf samples for pigment analyses were immediately frozen in a liquid nitrogen and stored in deep freeze $\left(-80^{\circ} \mathrm{C}\right)$ until being processed in a laboratory. Pigments were extracted according to the method of Porra et al. (1989) using the $80 \%$ acetone solvent and the pigment concentration was determined spectrophotometrically according to the empirical equations of Lichtenthaler (1987). Leaf pigment and water content values were converted from mass-based to area-based units using specific leaf area that is computed as the ratio between half of the hemisurface needle 


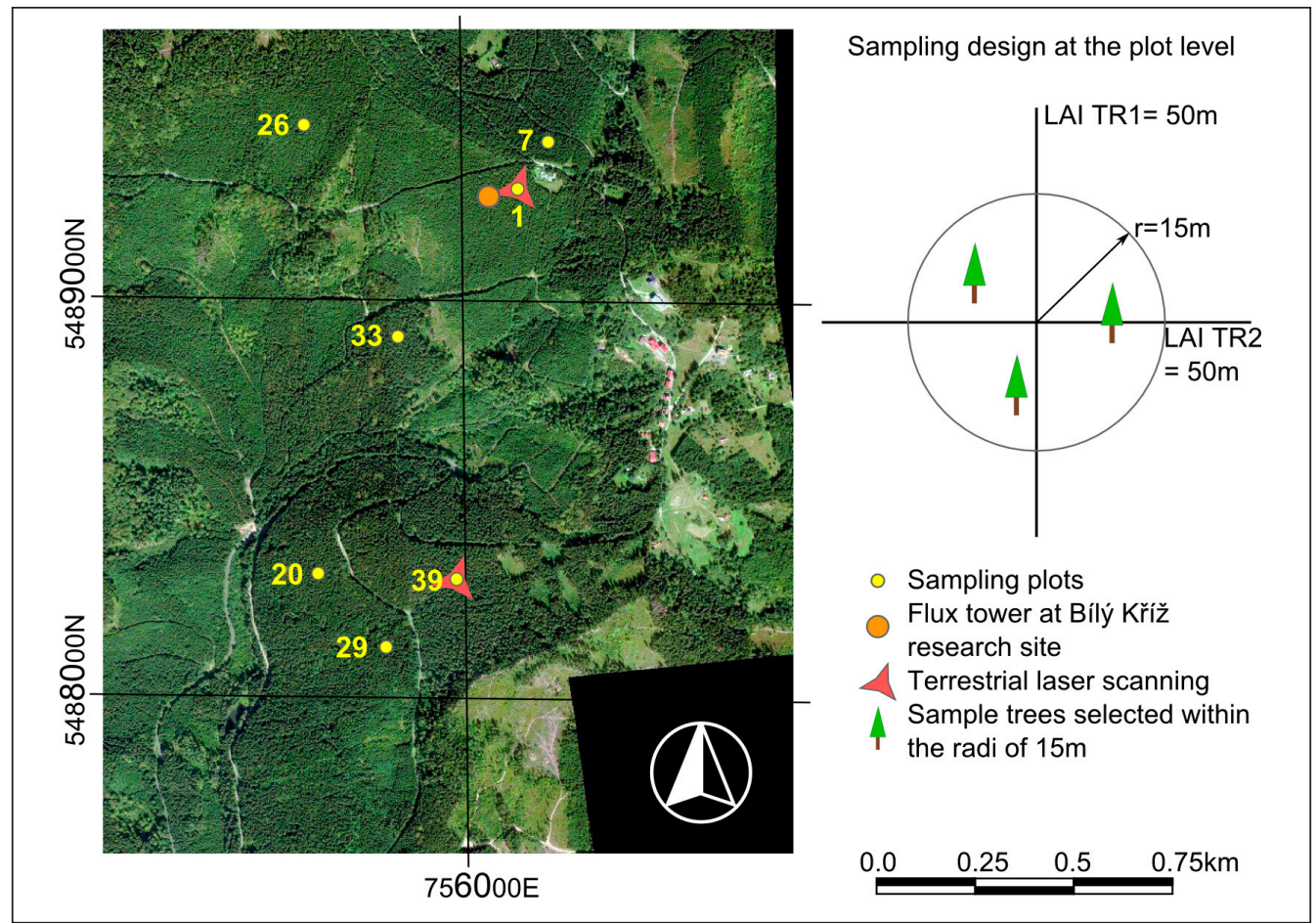

Fig. 1: In situ sampling plots at the Norway spruce dominated study site Bíly Kríž (left) and the sampling design for LAI and leaf biochemistry measurements (right).

area (Homolová et al. 2013) and the sample dry matter weight.

Leaf optical properties (LOP) between 350 and $2500 \mathrm{~nm}$, i.e., directional-hemispherical reflectance and transmittance factors (DHRF and DHTF), were measured using an assembly of two ASD FieldSpec spectroradiometers attached to ASD RTS-3ZC integrating spheres (Analytical Spectral Devices, Inc., Colorado, US). Each sphere was operated with a producedsupplied halogen light source. The ASD FieldSpec 4 with the first integrating sphere was used to measure hemisperically-integrated reflectance, the FieldSpec 3 attached to the second sphere was used to measure hemispericallyintegrated transmittance. This allowed for faster LOP measurements (it was not needed to change measurement mode of the sphere) and lower measurement uncertainty thanks to the fixed position of the light source. LOP measurement of narrow conifers needles is challenging (Yanez-Rausell et al. 2014a) and requires specifically designed carriers to place needles next to each other with small gaps in between (Malenovský et al. 2006; Yanez-Rausell et al. 2014b).
Gap fraction, i.e., percentage of gaps between needles within the illuminated part of a carrier was estimated from carrier scans with applied mask of the actual light beam position. Final reflectance (DHRF) and transmittance (DHTF) were computed using the following formulas:

$$
D H R F=\frac{\frac{(S A M P L E-S T R A Y) \times R_{S P E C T}}{W R-S T R A Y}}{1-G F}
$$

$$
D H T F=\frac{\frac{S A M P L E}{D N-G F W R-S T R A Y}}{1-G F}
$$

where SAMPLE is reflectance or transmittance of a needle sample measured in DN values, STRAY is stray light in DN values, $\mathrm{R}_{\mathrm{SPECT}}$ is reflectance of the inner sphere wall, WR is a white reference reflectance in DN values and GF is gap fraction for reflectance or transmittance sample, respectively. Final signatures of reflectance and transmittance were smoothed using a SavitskyGolay filter with 5th-degree degree polynomial. 


\section{Leaf area index}

Leaf area index of the spruce forest stand was measured using three optical instruments: Plant Canopy Analyser LAI-2200 (Li-cor Biosciences Inc., US), LaiPen (Photon Systems Instrument, $\mathrm{CZ}$ ) and digital hemispherical photographs (Canon 450D digital camera with Sigma $4.5 \mathrm{~mm}$ fisheye lens). Simultaneous measurements under diffuse sky conditions were taken at two $50 \mathrm{~m}$ long transects in a cross formation (Fig. 1). All three instruments measure so called effective LAIe (or plant area index), which must be further corrected from the effects of woody elements and foliage clumping in order to obtain "true" values LAIt (Chen 1996):

$$
\mathrm{LAIt}=(1-\alpha) * \mathrm{LAIe} * \gamma \mathrm{e} / \Omega \mathrm{e}
$$

where $\alpha$ is the woody-to-total plant area ratio, $\gamma e$ is the needle-to-total shoot area ratio and $\Omega \mathrm{e}$ is element clumping index. A correction factor between true and effective LAI was derived experimentally by Pokorný and Marek (2000) and Homolová et al. (2007) and it equals to LAIt = 1.6*LAIe.

\section{Terrestrial laser scanning data}

The 3D structure for selected trees at two plots (1 and 39) was measured using a terrestrial laser scanning system Riegl VZ-400 (Riegl Laser Measurement Systems, GmbH, Austria). Laser scanning inside a forest is challenging, because of mutual shadowing of neighborhood trees. In order to minimize the shadowing effect, the selected trees were scanned from multiple scan positions. The scan pattern (i.e., the angular step) of 10 mdeg resulted in the point spacing of $0.4 \mathrm{~cm}$ at the scanning distance between the scanner and a tree, which was about $20 \mathrm{~m}$.

Processing of point cloud data was done using RiSCAN PRO (post-processing software developed by Riegl). The point clouds obtained from scanning at multiple positions were merged together using white reference balls as tie points. The final point cloud was cleaned by filtering out points with high deviation value and segmented to individual trees. A point cloud resembling one tree was further classified into two groups, wooden element and green foliage, using an intensity threshold defined manually by an operator.

\section{Airborne imaging spectroscopy data}

Airborne imaging spectroscopy (or hyperspectral) data were acquired with two pushbroom spectroradiometers, CASI operating in the visible and near infrared regions between 372 and $1044 \mathrm{~nm}$ and SASI operating in the shortwave infrared region between 957 and $2442 \mathrm{~nm}$ (ITRES Research Limited, Canada). Both sensors were operated simultaneously on board the CzechGlobe Flying Laboratory of Imaging Systems (FLIS; Hanuš et al. 2016). Images were acquired under clear sky and sunny conditions on $31^{\text {st }}$ August 2016 in a high resolution mode (i.e., pixel size of $1 \mathrm{~m}$ for CASI and $2.5 \mathrm{~m}$ for SASI, 72 spectral bands for CASI and 100 bands for SASI). Corrections of the hyperspectral images were preformed according to a processing chain established at CzechGlobe (Hanuš et al. 2016). Radiometric corrections were performed using the factory calibration coefficients in the RCX software (post-processing software developed by ITRES that runs under ENVI/IDL programming environment). Geometric corrections, i.e. image orthorectification and geo-referencing, were performed using the GeoCorr software provided also by ITRES. Atmospheric corrections were performed using the ATCOR-4 software (Richter and Schläpfer 2002).

Simultaneously with the airborne data acquisition, spectral signatures of homogeneous artificial surfaces (e.g. asphalt, concrete, gravel fields) were measured in situ using the ASD FieldSpec 4 spectroradiometer. These spectral signatures were subsequently used to calibrate hyperspectral images and assess the quality of the atmospheric corrections.

\section{Results and Discussion}

\section{Leaf biochemical and optical properties}

Biochemical properties (leaf pigments, water content and specific leaf area) of Norway spruce needles are summarized in Table 1. The results show high variability among the needle samples collected from branches with contrasting illumination conditions (sunlit vs. shaded) and from shoots of different age (current vs. older needles). In particular, needles of the current year (c) have lower leaf pigments content, but higher specific leaf area (SLA) than older needles. 
For the sake of brevity, LOP, i.e., directionalhemispherical reflectance and transmittance factors of Norway spruce needles, are presented as mean and standard deviation computed from all the needle samples (Fig. 2.) Although the spectral signatures were measured between 350 and $2500 \mathrm{~nm}$, both ends of the spectral interval were too noisy and therefore discarded and the final signatures are presented between 400 and $2300 \mathrm{~nm}$. In general, spruce reflectance and transmittance spectra measured at the Bílý Kř̌́ž site are in agreement with other measurements of spruce trees for instance in Finland (Hovi et al. 2017; Lukeš et al. 2013). The leaf albedo, i.e., the sum of reflectance and transmittance, in the near infrared wavelengths is around 0.8 , which is lower than for broadleaf tree species (Hovi et al. 2017, Noda et al. 2014).

Although we present here only the mean spectral signatures, spectral differences between sunlit and shaded needles, as well as between needles of different age can be observed (see also Hovi et al. 2017 or Lukeš et al. 2013). Hovi et al. (2017) observed minor differences between sun exposed and shaded needles, but needle age was an important factor explaining variation particularly in needle transmittance. The spectral differences can be to some extend related to variations in leaf biochemistry. Leaf pigments are the main absorbing compounds influencing the optical properties in the visible and the red-edge region (400 - $720 \mathrm{~nm}$ ), whereas leaf structure (e.g. SLA) and water content are influencing optical properties in the near and short-wave infrared. Variation in needle biochemistry and optical properties can be partly considered as adaptation to different illumination conditions inside forest canopies (Niinemets 2010).

Measurement of LOP for coniferous needles is more prone to measurement errors than in case of deciduous flat leaves (Yanez et al. 2014a). This is mainly due to the irregular shape of narrow needles causing the gaps between the measured needles. The spectral measurements have to be corrected from the excess light penetrating through the gaps, therefore the gap fraction (ratio between the gaps and needles within the sample port) have to be precisely determined and corrected for (Yanez et al. 2014b).

\section{Leaf area index}

Leaf area index was measured using three optical instruments and the results in Fig. 3a shows that the LAI-2200 and LaiPen instruments provide similar measures of LAI, whereas hemispherical photography lower LAI compared to the other two instruments. The measurement principle of the two instruments (LAI-2200 and LaiPen) is similar; simultaneous below and above canopy readings are used to determine the canopy light interception at five zenith angles. The main difference between the two instruments is in their fields of view, LAI-2200 sees part of the hemisphere, whereas LaiPen measures within a narrow hemispherical sector. LaiPen measurements, however, are systematically higher than LAI-2200. Contrary, hemispherical photographs yielded lower and inconsistent estimates of spruce forest LAI.

Tab.1: Biochemical properties of Norway spruce needle samples collected from sunlit and shaded branches and from different needle age classes (c - current needles, $c$-1 - one-year-old needles, $c$-2 - two-years-old needles). Cab - leaf chlorophyll $a+b$ content, Car - leaf carotenoid content, $\mathrm{Ca} / \mathrm{Cb}$ - ratio between chlorophyll a and b, Cab/Car-ratio between chlorophylls and carotenoids, Cw-leaf water content, SLA-specific leaf area related to the needle hemisurface area.

\begin{tabular}{|c|c|c|c|c|c|c|}
\hline Branch & \multicolumn{3}{|c|}{ Sunlit } & \multicolumn{3}{|c|}{ Shaded } \\
\hline Needle age & c & c-1 & c-2 & c & c-1 & c-2 \\
\hline $\mathrm{Cab}\left[\mu \mathrm{g} \mathrm{cm}^{-2}\right]$ & $30.0 \pm 7.1$ & $40.5 \pm 7.3$ & $49.1 \pm 8.7$ & $25.2 \pm 5.2$ & $40.0 \pm 7.8$ & $40.6 \pm 6.3$ \\
\hline $\operatorname{Car}\left[\mu \mathrm{g} \mathrm{cm}^{-2}\right]$ & $6.1 \pm 1.5$ & $8.6 \pm 1.6$ & $10.6 \pm 1.9$ & $4.9 \pm 1.2$ & $6.9 \pm 1.7$ & $8.3 \pm 1.5$ \\
\hline $\mathrm{Ca} / \mathrm{Cb}[-]$ & $3.3 \pm 0.3$ & $3.2 \pm 0.2$ & $2.9 \pm 0.2$ & $3.2 \pm 0.3$ & $3.2 \pm 0.2$ & $3.0 \pm 0.2$ \\
\hline Cab/Car [-] & $5.0 \pm 0.4$ & $4.7 \pm 0.2$ & $4.6 \pm 0.2$ & $5.3 \pm 0.4$ & $5.0 \pm 0.2$ & $4.9 \pm 0.2$ \\
\hline $\mathrm{Cw}\left[\mathrm{mg} \mathrm{cm}^{-2}\right]$ & $21.4 \pm 3.5$ & $20.6 \pm 2.6$ & $22.8 \pm 2.3$ & $16.1 \pm 1.9$ & $16.2 \pm 2.6$ & $17.1 \pm 3.0$ \\
\hline SLA $\left[\mathrm{cm}^{2} \mathbf{g}^{-1}\right]$ & $69.7 \pm 13.5$ & $61.1 \pm 10.1$ & $49.3 \pm 7.3$ & $105.8 \pm 15.5$ & $92.2 \pm 17.3$ & $77.2 \pm 11.5$ \\
\hline
\end{tabular}




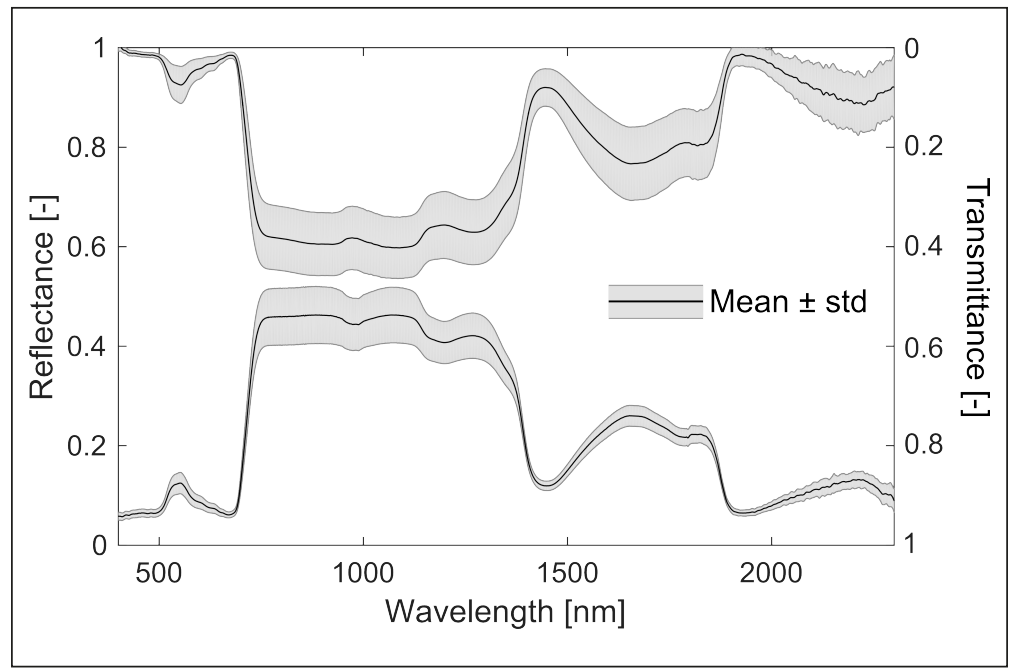

Fig. 2: Directional-hemispherical reflectance factor (bottom signature) and transmittance factor (upper signature) of Norway spruce needles.

Values of LAI (as measured by LAI-2200) varied between 5.3 and 9.3, which is in agreement with measurements done by Pokorný and Stojnič (2012), who measured LAI of 17 Norway spruce stands between 15 and 102 years located in the Těšínské Beskydy Mts. (NE part of the Czech Republic). Generally, the higher LAI values were measured in younger (cca 40 years old) than in older and sparser spruce stands (cca 100 years old).

Leaf area index and leaf biochemical properties were averaged in order to produce a single value per plot (Fig. 3 b). Leaf pigments vary little among the plots (e.g., Cab is between 32 and 41 $\mu \mathrm{g} \mathrm{cm}^{-2}$ ), but within plot variation is large (Cab std $\approx 10 \mu \mathrm{g} \mathrm{cm}^{-2}$ ) due to sampling of sunlit and shaded needles of different age. Contrary, LAI exhibits larger variation among the plots (LAI is between 5.3 and 9.3), but little variation within a plot is observed. Data aggregated at the plot level are geo-located and primarily used for the validation of the forest canopy parameters retrieved from airborne, as well as from satellite RS data.
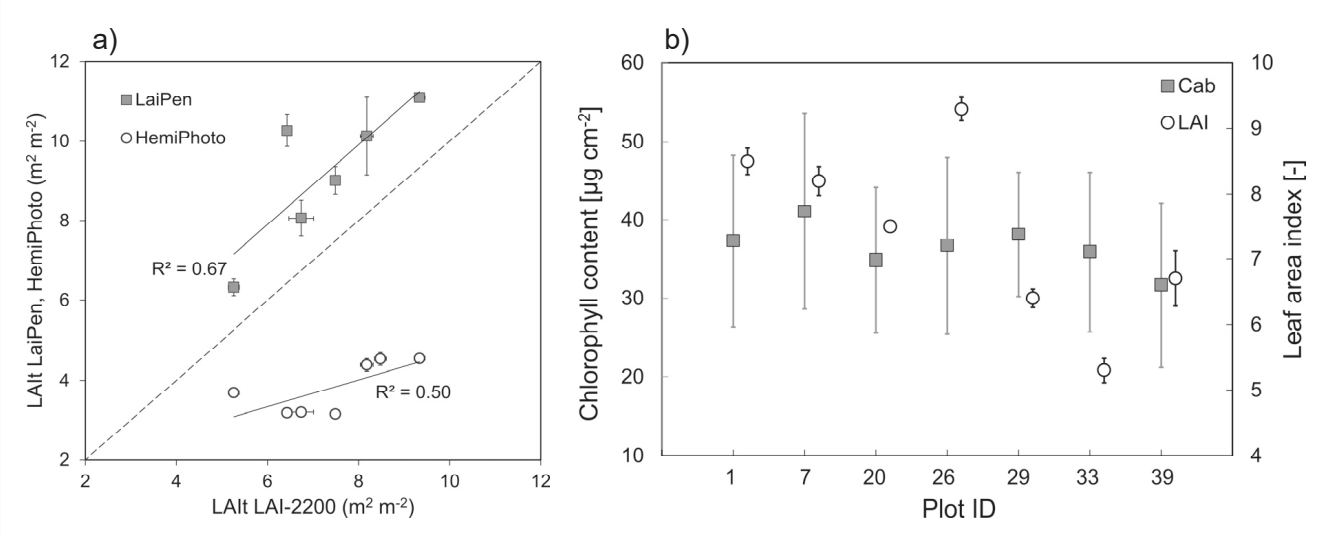

Fig. 3: Totalleaf area index (LAIt) of Norway spruce forest stands measured by three optical instruments, LAI-2200, LaiPen and hemispherical photography (a) and averaged leaf area index and leaf chlorophyll content per study plot (b). 


\section{Terrestrial laser scanning}

The terrestrial laser scanning allows extracting the exact 3D tree architecture (Hackenberg et al., 2014), including information about a stem, main branches and spatial distribution and density of foliage. The point cloud data of individual trees were first differentiated to wooden and foliage elements and subsequently used to reconstruct trees as 3D objects (Fig. 4.). The entire modelling procedure was developed by Janoutová (2017) and it can be briefly summarized by three main steps:

1) reconstruction of wooden skeleton including trunk and main branches (Fig. 4b),

2) scaling and transformation of the foliage point cloud and the reconstructed wooden skeleton to a site-specific tree dimensions,

3) distribution of needle shoot models within a tree crown according to the density of the foliage point cloud (Fig. 4c).

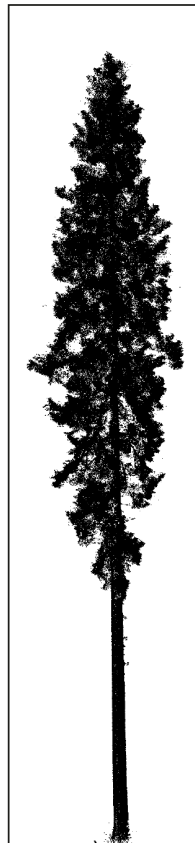

a)

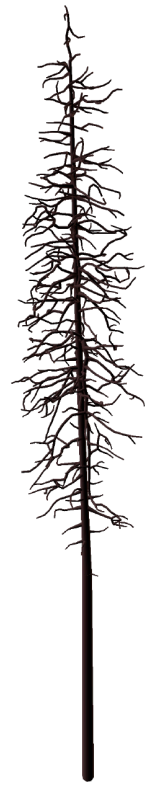

b)

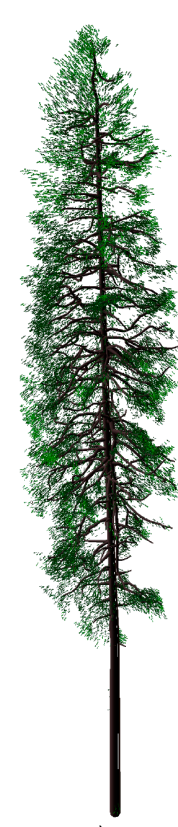

c)
Fig. 4: Example of point cloud data for a single spruce tree obtained from the terrestrial laser scanning (a), reconstructed stem and main branches (b), and the final 3D spruce tree model composed of wooden and foliage objects (c).
In the context of the optical remote sensing of forests, the ability to create plausible 3D tree models would improve the radiative transfer modelling of spruce canopies, where the canopy structure plays an important role in the near and short-wave infrared spectral regions. Althgough, there currently are radiative transfer models available (e.g., DART) that can accommodate trees as 3D objects, computation of the radiative transfer for larger forest scenes still can be very demanding. Nevertheless, the 3D radiative transfer modelling could be better tailored for site-specific conditions thus enabling to develop robust retrieval methods for structurally complex forested areas.

\section{Airborne imaging spectroscopy data}

The final result of the airborne data acquisition is the geometrically and atmospherically corrected hypercube image mosaic of several flight lines covering the study area (only small image subsets extracted around the vicinity of the Bílý Kř́ž ecosystem station are shown in Fig. 5 - left panels). The final image mosaics were created separately for CASI (covering the visible and near infrared regions with the pixel size of $1 \mathrm{~m}$ ) and SASI (covering the near and short-wave infrared regions with the pixel size of $2.5 \mathrm{~m}$ ). Seamless combination of CASI and SASI image data of two different spatial resolutions into a single hypercube that covers the entire spectral range from 400 to $2500 \mathrm{~nm}$ turned out to be difficult for heterogeneous areas because of the mismatch in spectral resolution and. It will be further investigated how to better combine CASI and SASI image data for heterogeneous forest surfaces on per pixel basis.

The quality of the atmospheric corrections was evaluated by comparing the image spectra extracted from homogeneous artificial surfaces (such as parking place, asphalt road) and their counterparts measured in situ. The visual comparison shows good agreement between the image and in situ spectra (for brevity results are not shown) with maximum differences of about $3 \%$ in the short-wave infrared bands. 

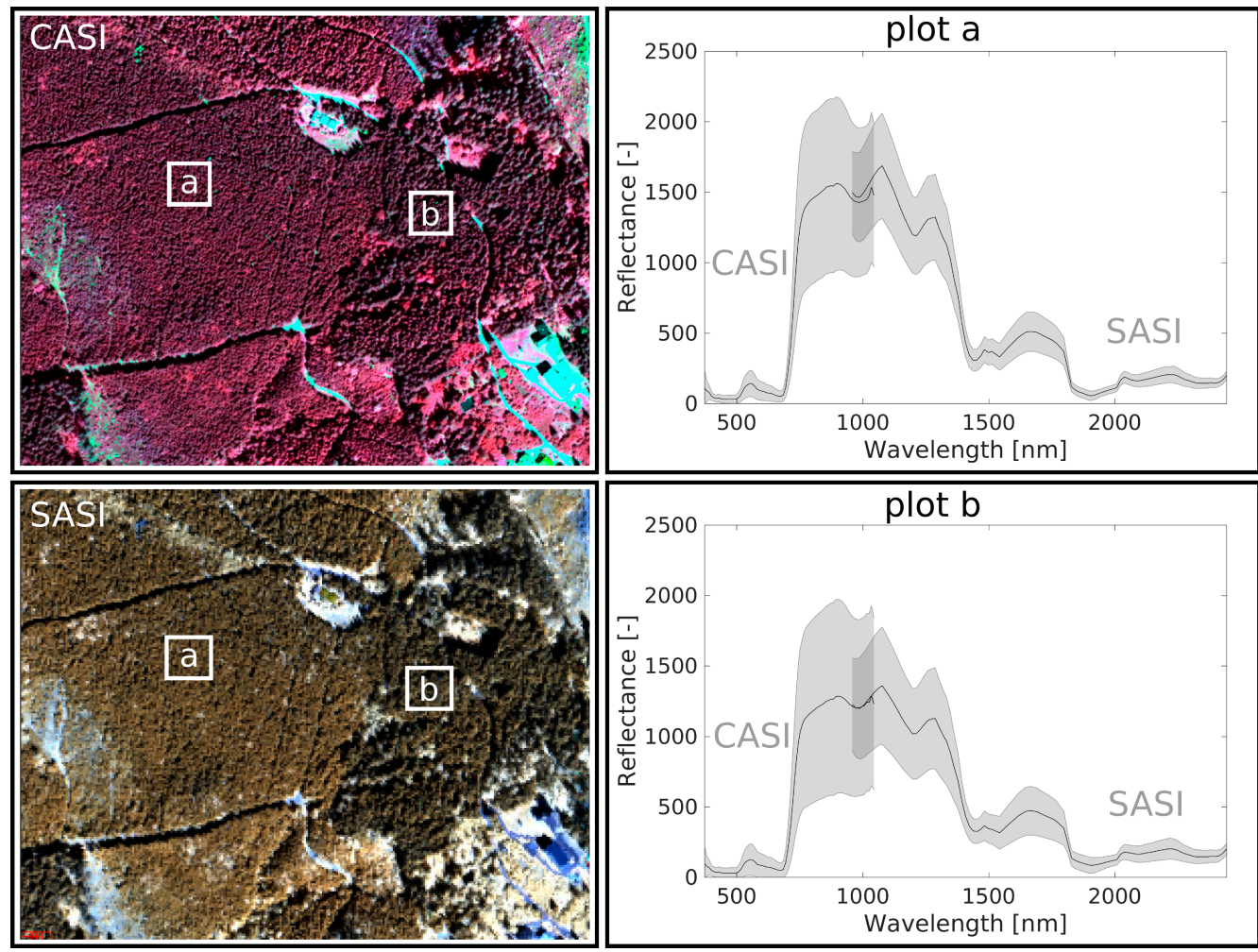

Fig. 5: Left panels show subsets of airborne hyperspectral images acquired at the Bily Krrî̌ study site by CASI (pixel size of $1 \mathrm{~m}$ displayed as false colour composite $R-864 \mathrm{~nm}, \mathrm{G}-647 \mathrm{~nm}, \mathrm{~B}-552 \mathrm{~nm}$ ) and SASI (pixel size of $2.5 \mathrm{~m}$ displayed as false colour composite $R-1062 \mathrm{~nm}, \mathrm{G}-1243 \mathrm{~nm}, \mathrm{~B}-1692 \mathrm{~nm}$ ) spectroradiometers. Right panels show examples of canopy spectral signatures extracted for two plots representing spruce forest of about 40 years old (plot a) and 80 years old (plot $b$ ).

\section{Conceptual framework for the retrieval of forest quantitative parameters}

All the in situ and airborne data discussed up to this point fit into a broader conceptual framework for the estimation of quantitative forest parameters from RS data (Fig. 6.). Radiative transfer modelling plays the central role in the framework as it effectively enables to scale the in situ leaf optical and biochemical properties and canopy structural measurements up to the level of airborne and satellite remote sensing reflectance observations. Therefore, forest parameters, such as leaf pigment and water content, leaf area index, canopy cover, that are at the same time the key input parameters of the forest RTM, can be estimated from RS data (Rautiainen et al., 2010).

In situ measurements contribute more or less to all steps of the retrieval framework and they can be divided into several groups according their role (Fig. 6). First, in situ data are used to correct RS images and these typically include measurements of the actual atmospheric conditions and reflectance of reference ground targets. Second, in situ data are used to parameterize radiative transfer models and these include terrestrial laser scanning data enable to model forest canopies in realistic 3D way, optical properties of needles and other forest elements (e.g., bark, forest floor cover), as well as variation and distribution of key vegetation parameters that are used as RT model inputs. Third, in situ measurements of vegetation parameters that are estimated from RS data (e.g., pigment, water content, LAI) which provide an independent validation of the RS-based products. 


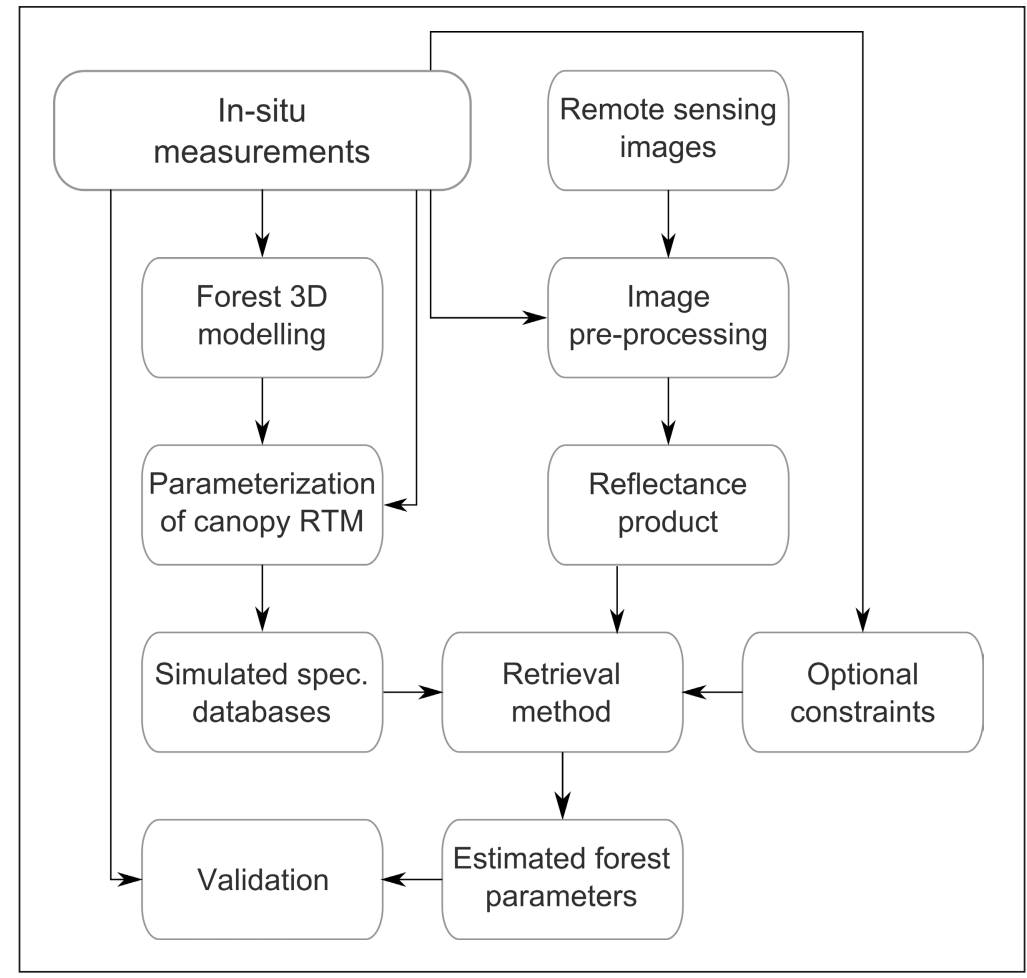

Fig. 6: Contribution of the in situ measurements to the framework for retrieval of forest quantitative parameters from remote sensing data using the radiative transfer modelling (RTM).

\section{Conclusions}

Establishing a retrieval chain for quantitative estimation of vegetation parameters from RS data requires strong support from multitude in situ measurements. We introduced here different types of in situ data and their measurement methods that are relevant for our case study presented for airborne remote sensing assessment of Norway spruce forests. In situ measurements include leaf biochemical properties that together with LAI data are primarily used for validation of RS-base products. Leaf chlorophyll content varied between 25.2 and $49.1 \mu \mathrm{g} \mathrm{cm}^{-2}$, carotenoids between 4.9 and $10.6 \mu \mathrm{g} \mathrm{cm}^{-2}$, leaf area index varied between 5.3 and $9.3 \mathrm{~m}^{2} \mathrm{~m}^{-2}$. Leaf optical properties, i.e., reflectance and transmittance are essentially used for verification and improvement of forest RT modelling. Terrestrial laser scanning data are used to model forests in 3D and such as they can improve RT modelling for forests. In this case, several trees could be extracted from the point cloud data, reconstructed using the approach developed by Janoutová (2017) and used to build-up a forest canopy scene for simulating large spectral database in the DART radiative transfer model. At the end, we presented the acquisition of airborne hyerpsectral images of the spruce study site with accompanying in situ measurements of ground reference targets to verify the quality of the image pre-processing (i.e., atmospheric corrections).

A combination of in situ and RS data can reduce uncertainty in area-wide mapping of forest biochemical and biophysical parameters. The proposed conceptual framework can be helpful to assess the potential of new satellite missions (i.e., Sentinels, FLEX) with its focus on identifying environmental processes. This framework has been implemented by CzechGlobe in the context of the ESA research projects related to exploiting the Sentinel-2 red-edge or airborne hyperspectral bands for the retrieval of vegetation biochemical and biophysical parameters. 


\section{Acknowledgement}

This work was supported by the Ministry of Education, Youth and Sports of CR within the National Sustainability Program I (NPU I), grant number LO1415 and by the European Space Agency grant number 4000115955/15/NL/AF.

\section{References}

Asner, G.P., Martin, R.E., Anderson, C.B., KnapP, D.E. 2015: Quantifying forest canopy traits: Imaging spectroscopy versus field survey. Remote Sensing of Environment, 158: 15-27.

Banskota A, Serbin, S.P., Wynne, R.H., Thomas, V.A., Falkowski, M.J., Kayastha, N, GastelluETCHEGorRY, J.-P., TOWNSEND, P.A. 2015: An LUT-Based Inversion of DART Model to Estimate Forest LAI from Hyperspectral Data. IEEE Journal of Selected Topics in Applied Earth Observations and Remote Sensing, 8(6): 3147-3160.

CHEN, J.M. 1996: Optically-based methods for measuring seasonal variation of leaf area index in boreal conifer stands. Agricultural and Forest Meteorology, 80(2-4): 135-163.

Cohen, W.B., Goward, S.N. 2004: Landsat's role in ecological applications of remote sensing. BioScience, 54: 535-545.

ERIKSSON, H.M., EKLundh, L., KuUsK, A., Nilson, T. 2006: Impact of understory vegetation on forest canopy reflectance and remotely sensed LAI estimates. Remote Sensing of Environment, 103: 408-418.

Gastellu-Etchegorry, J.-P., Yin, T., Lauret, N., Cajgfinger, T., Gregoire, T., Grau, E., Feret, J.B., Lopes, M., ET Al. 2015: Discrete Anisotropic Radiative Transfer (DART 5) for Modeling Airborne and Satellite Spectroradiometer and LIDAR Acquisitions of Natural and Urban Landscapes. Remote Sensing, 7: 1667-1701.

Hackenberg, J., Morhart, C., Sheppard, J., SPIECKer, H., Disney, M. 2014: Highly Accurate Tree Models Derived from Terrestrial Laser Scan Data: A Method Description. Forests, 5(5): 1069-1105.

Hanuš, J., FabiáneK, T., Fajmon, L. 2016: Potential of airborne imaging spectroscopy at CzechGlobe. International Archives of the Photogrammetry, Remote Sensing and Spatial Information Scinces, XLI-B1: 15-17. https://doi.org/10.5194/ isprs-archives-XLI-B1-15-2016.

Heiskanen, J., Rautiainen, M., Stenberg, P., MõtTUS, M., Vesanto, V-H. 2013: Sensitivity of narrowband vegetation indices to boreal forest
LAI, reflectance seasonality and species composition, In ISPRS Journal of Photogrammetry and Remote Sensing, Volume 78: 1-14.

Homolová, L., Lukeš, P., Malenovský, Z., LhotÁKovÁ, Z., Kaplan, V., Hanuš, J. 2013: Measurement methods and variability assessment of the Norway spruce total leaf area: implications for remote sensing. Trees - Structure and functions, 27: 111-121.

Homolová, L., MalenovskÝ, Z., Hanuš, J., TomÁšKovÁ, I., DVoŘÁkOVÁ, M., PoKORNÝ, R. 2007: Comparison of different ground techniques to map leaf area index of Norway spruce forest canopy. ISPRS Archives Volume XXXVI-7/C50: 499-504. Available online http://www.isprs.org/proceedings/ XXXVI/7-C50/papers/P95.pdf

Hovi, A., Raitio, P., Rautiainen, M. 2017: A spectral analysis of 25 boreal tree species. Silva Fennica, $51(4): 7753$.

Jacquemoud, S., Verhoef, W., Baret, F., Bacour, C., Zarco-tejada, P.J., Asner, G.P., Francois, C., Ustin, S.L. 2009: PROSPECT + SAIL models: A review of use for vegetation characterization. Remote Sensing of Environment, 113: 56-66.

JanoutovÁ, R. 2017: Modelling 3D forest structure for improved retrieval of forest biophysical properties. Brno University of Technology, Faculty of Mechanical Engineering, Brno. 100 pp.

Kokaly, R.F., Asner, G.P., Ollinger, S.V., Martin, M.E., Wessman, C.A. 2009: Characterizing canopy biochemistry from imaging spectroscopy and its application to ecosystem studies. Remote Sensing of Environment, 113: 78-91.

Krupková, L., Marková, I., Havránková, K., Pokorný, R., Urban, O., Šigut, L., Pavelka, M., Cenciala, E., Marek, M.V. 2017: Comparison of different approaches of radiation use efficiency of biomass formation estimation in Mountain Norway spruce. Trees - Structure and Functions, 31(1): 325-337.

Laurent, V.C.E., Verhoef, W., Clevers, J.G.P.W., SCHAEPMAN, M.E. 2011: Inversion of a coupled canopy-atmosphere model using multi-angular top-of-atmosphere radiance data: A forest case study. Remote Sensing of Environment, 115: 2603-2612.

Lausch, A., Erasmi, S., King, D.J., Magdon, P., Heurich, M. 2016: Understanding forest health by remote sensing Part I - A review of spectral traits, processes and remote sensing characteristics. Remote Sensing, 8: 1029.

Lausch, A., Erasmi, S., King, D.J., Magdon, P., Heurich, M. 2017: Understanding forest 
health by remote sensing Part II - A review of approaches and data models. Remote Sensing, 9: 129.

LichtentHALER, H.K. 1987. Chlorophylls and carotenoids: Pigments of photosynthetic membranes. Methods in Enzymology, 148: 350-382.

Lukeš, P., Stenberg, P., Rautiainen, M., Mõttus, M., Vanhatalo, K.M. 2013: Optical properties of elaves and needles for boreal tree species in Europe. Remote Sensing Letters, 4(7): 667-676.

Malenovský, Z., Martin, E., Homolová, L., Gastellu-Etchegorry, J-P., ZuRita-Milla, R., Schaepman, M.E., Pokorný, R., Clevers, J.G.P.W., CudLín, P. 2008: Influence of woody elements of a Norway spruce canopy on nadir reflectance simulated by the DART model at very high spatial resolution. Remote Sensing of Environment, 112: 1-18.

MalenovskÝ, Z., Albrechtová, J., Lhotáková, Z., Zurita-Milla, R., Cleverer, J.G.P.W., SchaepMAN, M.E., CudLín, P. 2006: Applicability of the PROSPECT model for Norway spruce needles. International Journal of Remote Sensing, 24: 5315-5340.

Malenovský, Z., Homolová, L., Zurita-Milla, R., Lukeš, P., Kaplan, V., Hanuš, J., Gastellu-EtchEGORRY, J.-P., SCHAEPMAN, M.E., 2013. Retrieval of spruce leaf chlorophyll content from airborne image data using continuum removal and radiative transfer. Remote Sensing of Environment, 131: 85-102.

Middleton, E.M., Rascher, U., CoRp, L.A., HuemMrich, K.F., COOK, B.D., NoORMETS, A., SCHICKling, A., Pinto, F., Alonso, L., Et AL. 2017: The 2013 FLEX-US Airborne Campaign at the Parker Tract Loblolly Pine Plantation in North Carolina, USA. Remote Sensing, 9: 612.

NiINEMETS, Ü. 2010: A review of light interception in plant stands from leaf to canopy in different plant functional types and in species with varying shade tolerance. Ecological Research, 25: 693-714.

Noda, H.M., Мotohka, T., Murakami, K., MuraOKA, H., NASAHARA, K.N. 2015. Reflectance and transmittance spectra of leaves and shoots of 22 vascular plant species and reflectance spectra of trunks and branches of 12 tree species in Japan. Ecological Research, 29: 111.

Pause, M., Schweitzer, C., Rosenthal, M., Keuck, V., Bumberger, J., Dietrich, P., et Al. 2016: In situ/remote sensing integration to assess forest health - a review. Remote Sensing, 8(6): 471.

Pokorný, R., Marek, M.V. 2000: Test of accuracy of LAI estimation by LAI-2000 under artificially changed leaf to wood area proportions. Biologia Plantarum, 43(4): 537-544.

PoKoRnÝ, R., SтоJNič, S. 2012: Leaf area index of Norway spruce stands in relation to age and defoliation. Beskydy, 5(2): 173-180.

Porra, R.J., Thompson, W.A., Kriedemann, P.E. 1989: Determination of accurate extinction coefficients and simultaneous equations for assaying chlorophylls a and b extracted with four different solvents: verification of the concentration of chlorophyll standards by atomic absorption spectroscopy. Biochem Biophys Acta, 975: 384-394.

Rautiainen, M., Stenberg, P., Nilson, T., Kuusk, A. 2004: The effect of crown shape on the reflectance of coniferous stands. Remote Sensing of Environment 89: 41-52.

Rautiainen, M., Heiskanen, J., Eklundh, L., MõtTUS, M., LuKEŠ, P., STENBERG, P. 2010: Ecological application of physically based remote sensing methods. Scandinavian Journal of Forest Research, 25: 325-339.

Richter, R., SCHLÄPFER, D. 2002: Geo-atmospheric processing of airborne imaging spectrometry data. Part 2: Atmospheric/topographic correction. International Journal of Remote Sensing, 23: 2631-2649.

Rochdi, N., Fernandes, R., Chelle, M. 2006: An assessment of needles clumping within shoots when modeling radiative transfer within homogeneous canopies. Remote Sensing of Environment, 102: 116-134.

Rossini, M., Nedbal, L., Guanter, L., Ač, A., Alonso, L., Burkart, A., Cogliati, S., Colombo, R., Damm, A., Drusch, M., Hanuš, J., Janoutová, R., ET AL. 2015: Red and far red Sun-induced chlorophyll fluorescence as a measure of plant photosynthesis. Geophys. Res. Lett., 42: 1632-1639.

SchaEpMAN, M.E. 2009: Imaging Spectrometers. In: Warner TA, Duane Nellis M, Foody GM (eds) The SAGE Handbook of Remote Sensing. SAGE, London (UK), pp. 166-178.

SCHLERF, M., AtZberger, C. 2006: Inversion of a forest reflectance model to estimate structural canopy variables from hyperspectral remote sensing data. Remote Sensing of Environment, 100: 281-294.

Urban, O., Klem, K., Ač, A., Havránkovâ, K., Holišová, P., NAVRÁtiL, M., ET AL. 2012: Impact of clear and cloudy sky conditions on the vertical distribution of photosynthetic CO2 uptake within a spruce canopy. Functional Ecology, 26(1): 46-55. 
Verhoef, W., Bach, H. 2007: Coupled soil-leafcanopy and atmosphere radiative transfier modeling to simulate hyperspectral multiangular surface reflectance and TOA radiance data. Remote Sensing of Environment, 109: 166-182.

Yanez-Rausell, L., Schaepman, M.E., Clevers, J.G.P.W., MalenovsKÝ, Z. 2014a: Minimizing measurement uncertainties of coniferous needle-leaf optical properties, part i: Methodological review. IEEE Journal of Selected Topics in Applied Earth Observations and Remote Sensing, 7(2): 399-405.

Yanez-Rausell, L., Malenovský, Z., Cleverers, J.G.P.W., Schaepman, M.E. 2014 b: Minimizing measurement uncertainties of coniferous needle-leaf optical properties. Part II: Experimental setup and error analysis. IEEE Journal of Selected Topics in Applied Earth Observations and Remote Sensing, 7(2): 406-420. 